\title{
Understanding hand hygiene behavior in a pediatric oncology unit in a low- to mid-income country
}

\author{
Miriam L. González ${ }^{1}$, Ruthbeth Finerman², Kyle M. Johnson ${ }^{1}$, Mario Melgar ${ }^{3}$, Maria Mercedes Somarriba ${ }^{4}$, Federico \\ Antillon-Klussmann ${ }^{3}$, Miguela Ayala Caniza *1,5,6 \\ ${ }^{1}$ Department of Infectious Diseases, St. Jude Children's Research Hospital, Memphis, TN, USA \\ ${ }^{2}$ Department of Anthropology, The University of Memphis, Memphis, TN, USA \\ ${ }^{3}$ Unidad Nacional de Oncologia Pediatrica, Guatemala City, Guatemala \\ ${ }^{4}$ Hospital Infantil Juan Manuel Rivera, Managua, Nicaragua \\ ${ }^{5}$ Department of Global Pediatric Medicine, St Jude Children's Research Hospital, Memphis, TN, USA \\ ${ }^{6}$ International Outreach Program, St. Jude Children's Research Hospital, Memphis, TN, USA
}

Received: March 4, 2016

DOI: $10.5430 /$ jnep.v6n9p1
Accepted: March 30, 2016

Online Published: April 19, 2016

\begin{abstract}
Objective: A qualitative method study identified perceived barriers and motivations for hand hygiene $(\mathrm{HH})$ practice in a pediatric oncology unit in Guatemala.

Methods: Data collection included focus groups with participants grouped by job type. Focus group responses were assessed using content analysis. Participants included nurse supervisors, registered nurses, auxiliary nurses, physicians, and auxiliary and support staff and volunteers $(\mathrm{n}=55)$.

Results: Themes emerged from participant responses, providing a framework to develop and implement targeted interventions to improve HH. Perceived barriers to $\mathrm{HH}$ included the following themes: inconsistent $\mathrm{HH}$ supplies, time pressures related to workload, lack of HH training for some healthcare workers and patients' families; negative social reactions after reminding others to practice $\mathrm{HH}$; and cultural traditions shaping patients' families' hygiene. Motivations for HH practice included two themes: patient protection and self-protection. Some of these themes were unique to this culture and clinical setting. Recommendations included a preference for visual aids rather than verbal reminders (e.g. HH promotion signage, demonstrations of $\mathrm{HH}$ ), and disclosure of compliance rates.

Conclusions: The research team concluded that the main barriers and motivations for $\mathrm{HH}$, including culturally-unique and site-specific factors, were identified and used for subsequent $\mathrm{HH}$ compliance improvement such as education. Intervention post focus group concentrated in $\mathrm{HH}$ education of healthcare providers using e-learning methodology.
\end{abstract}

Key Words: Hand hygiene, Healthcare-associated infections, Low- to mid-income countries, Pediatric, Cancer, Social norms

\section{INTRODUCTION}

Healthcare-associated infection (HAI) rates are markers of healthcare quality worldwide. Hand hygiene $(\mathrm{HH})$, either by washing with soap or rubbing with alcohol gel, is ef- fective in preventing HAIs. ${ }^{[1]}$ However, HH compliance is generally suboptimal, depending on the availability of $\mathrm{HH}$ infrastructure and supplies, knowledge and attitudes about $\mathrm{HH}$, and cultural and social norms. ${ }^{[1-3]}$ While HH compli-

\footnotetext{
*Correspondence: Miguela Ayala Caniza; Email: miguela.caniza@ stjude.org; Address: St. Jude Children’s Research Hospital, 262 Danny Thomas Place MS721 Memphis, TN 30105, USA. 
ance is supported by sufficient sinks, supplies, education, and promotion, ${ }^{[4,5]}$ these factors are often deficient or absent at healthcare institutions in low- to mid-income countries (LMIC). ${ }^{[6,7]}$

HAIs are the main cause of treatment-related morbidity and mortality in immunocompromised patients at the Unidad Nacional de Oncología Pediátrica (UNOP), ${ }^{[8,9]}$ Guatemala's national pediatric oncology hospital. For more than a decade, the department of Infectious Diseases and the International Outreach Program of St. Jude Children's Research Hospital have provided mentoring and training to UNOP staff in infection care and prevention. ${ }^{[10,11]}$ In 2008 , this collaboration supported the creation of a UNOP infection care and prevention (ICP) team comprising an infectious disease physician, 2 nurse preventionists, and a data manager. Better HH compliance became an essential task for the ICP team since its inception. Despite improvement of $\mathrm{HH}$ supplies by placement of one alcohol gel dispenser per each two beds and improvement of awareness through annual $\mathrm{HH}$ education and promotion, observations of $\mathrm{HH}$ practices, rates of gel consumption, and rates of infection indicated that the rate of $\mathrm{HH}$ compliance at UNOP was as low as $30 \%$. Compliance increased temporarily after the ICP team's periodic distribution of personal alcohol gel dispensers, and celebration of Hand Hygiene and Infection Prevention Week. However, despite these interventions, $\mathrm{HH}$ rates fluctuated, leading the research team to investigate $\mathrm{HH}$ practices and perceived barriers and motivations to $\mathrm{HH}$ compliance at UNOP.

$\mathrm{HH}$ practices among healthcare staff are closely associated with attitudes, beliefs, and customs, ${ }^{[1,12-14]}$ which are readily assessed through focus group studies. Focus groups can yield rich qualitative information about cultural patterns and contexts that shape beliefs and behaviors, and they can elicit unanticipated findings (e.g., new questions for subsequent surveys) or site-specific factors. ${ }^{[15,16]}$ Focus groups are also an informative tool for characterizing different ways in which participants experience a similar procedure, in this case $\mathrm{HH}$. Here we report the result of a focus group study which was conducted to better understand site-specific determinants of $\mathrm{HH}$ practice in a pediatric cancer unit in Guatemala.

\section{MeTHODS}

\subsection{Setting}

UNOP, a semiautonomous public pediatric cancer unit in Guatemala City, cares for more than 400 children with cancer and sees approximately 300 new patients every year. In 2011, $17 \%$ (55 of 321) of patients at UNOP were Guatemalan from traditional Mayan communities, the rest were Mestizos and of European descent and few from neighboring countries. UNOP has 42 beds, with a $90 \%$ occupancy rate. Hospi- tal Roosevelt, a public general hospital adjacent to UNOP, provides resources for surgery. UNOP employs 104 nurses (including 11 nurse supervisors), 35 physicians, 13 pharmacy staff, 9 respiratory therapists, 8 phlebotomists, 6 nutritionists, and 19 cleaning staff. Approximately 20 non-medical volunteers assist in tasks involving patient and family contact.

\subsection{Participants}

All categories of employees were invited to participate in the study. On-site investigators used pre-established meetings to inform UNOP staff about the study and recruit participants. For participants to be eligible, they were required to be part of the UNOP and working as a doctor, nurse, pharmacist, respiratory therapist, nutritionist, volunteer, or cleaning staff. Once a participant was matched to the specific focus group session, which was based on the type of job, the participant's verbal agreement to attend the focus group meeting signified their consent to participate in the study.

\subsection{UNOP infection care and prevention program}

Since 2008, a team comprising of an infectious disease physician, 2 nurse preventionists, and a data manager has supported the ICP program at UNOP. The team meets monthly to review ongoing HAI surveillance and plan for ICP improvement. They also provide education to staff, patients, and families and oversee daily ICP issues, including $\mathrm{HH}$ supplies.

\subsection{Ethical approval}

This study was approved by the Research Ethics Committee of Francisco Marroquin University, Guatemala and the Institutional Review Board of St. Jude Children's Research Hospital. The study was determined to be of minimal risk to participants. The requirement for written informed consent was waived, but the verbal informed consent of participants was required. This consent was obtained from participants by reading a consent script at the start of each session and reminding the participants that their comments during the focus group sessions were confidential.

\subsection{Design of main questions and follow-up questions}

We designed mainly open-ended questions to identify perceived barriers and motivations to the practice of $\mathrm{HH}$. On the basis of a review of $\mathrm{HH}$ studies in the literature ${ }^{[1-4,12-14,17]}$ and the expertise of our study team members in $\mathrm{HH}$ and Spanish as a first (MLG, MMS, MAC) or second (KMJ, RF) language, we constructed and refined the questions listed in Table 1. 
Table 1. Questions and follow-up questions asked of focus group participants

\begin{tabular}{|c|c|}
\hline $\begin{array}{l}\text { Question } \\
\text { No. }\end{array}$ & Main questions and follow-up questions \\
\hline 1 & $\begin{array}{l}\text { Do you believe that you and your coworkers always practice } \\
\text { HH when you should when you are at work? } \\
\text { a. What does "always" mean to you? } \\
\text { b. Why or why not do they always practice HH? }\end{array}$ \\
\hline 2 & $\begin{array}{l}\text { What is the most important impediment or barrier to HH? } \\
\text { a. Are there other barriers to practicing HH? Other } \\
\text { opinions? } \\
\text { b. What would you do to reduce the effect of these barriers? } \\
\text { Other solutions? }\end{array}$ \\
\hline 3 & $\begin{array}{l}\text { Think about a recent opportunity in which you did not } \\
\text { practice HH. What was the main reason you did not practice } \\
\text { HH? } \\
\text { a. How could this situation have been avoided? }\end{array}$ \\
\hline 4 & $\begin{array}{l}\text { Have you ever reminded someone else about the indications } \\
\text { to practice HH? } \\
\text { a. Can you share an experience? } \\
\text { b. Why or why not have you reminded others to practice } \\
\text { HH? }\end{array}$ \\
\hline 5 & $\begin{array}{l}\text { Is there a particular person or group of people whose } \\
\text { reminder about the indications for } \mathrm{HH} \text { would make you feel } \\
\text { uncomfortable? }\end{array}$ \\
\hline 6 & $\begin{array}{l}\text { Does it make you uncomfortable to see a family of a patient } \\
\text { not practice HH? } \\
\text { a. Have you ever taken action in this type of situation? }\end{array}$ \\
\hline 7 & $\begin{array}{l}\text { Think of a recent situation in which you felt that you should } \\
\text { practice HH. } \\
\text { a. What happened that made you feel the need to practice } \\
\text { HH? } \\
\text { b. Have others had different experiences? }\end{array}$ \\
\hline 8 & $\begin{array}{l}\text { Think of the training or classes that you have received in } \\
\text { HH. What is something that you remember from this that } \\
\text { makes you want to practice HH? } \\
\text { a. What experiences can others share? }\end{array}$ \\
\hline 9 & $\begin{array}{l}\text { Are you in agreement or disagreement with the following } \\
\text { statement: Your coworkers are convinced that the practice } \\
\text { of HH prevents infection? } \\
\text { a. Who is protected from infection by HH? } \\
\text { b. Give an example. } \\
\text { c. Are there other, different opinions? }\end{array}$ \\
\hline 10 & $\begin{array}{l}\text { What suggestions do you have to help us motivate everyone } \\
\text { to practice HH and to improve the HH program? }\end{array}$ \\
\hline
\end{tabular}

\subsection{Focus group sessions}

All categories of employees were represented in the focus groups. Six groups of 8-12 consenting participants (total $n=$ 55) were formed on the basis of job type: (1) nurse supervisors, (2) registered nurses, (3) auxiliary nurses, (4) pediatricians, (5) auxiliary staff (respiratory therapists, pharmacists, laboratory technicians, nutritionists, and therapy nurse), and (6) volunteers and cleaning staff. We reasoned that jobspecific groups would encourage participants to speak freely. Because of the mandatory nature of established UNOP employees meetings, we believed that the invitation to participate in the study was extended to most of the employees.
Patients and their family members were not asked to participate in this study. Although their practice of HH is important, their level of training in ICP was not comparable to that of hospital staff.

Six focus group sessions (one per job category) were conducted in August 2011, using the same 10 questions and follow-up questions. Only moderators and participants attended the sessions, which were audio-recorded. Participants were encouraged to give candid answers and were assured of confidentiality. To avoid introducing bias into subsequent sessions, participants were asked not to discuss the focus groups afterward. Each session began with an "icebreaker" question not included in the analysis.

The focus groups were moderated by native speakers of Spanish (MMS and MLG) who were not employed by or affiliated with UNOP. The focus group rapporteur (RF) was experienced in conducting focus groups and fluent in Spanish. The rapporteur took handwritten notes at each session. Participants' responses were identified by seat number. Written notes included direct quotes accompanied by seat number and the number of participants who agreed or disagreed with questions, statements, or topics raised in sessions (e.g., seat numbers of participants who raised their hands, nodded their heads, or verbally agreed with a statement). Identifying participants by seat number allowed us to maintain confidentiality and avoid overrepresentation of single individuals in the analysis. Strength of opinion about a HH barrier or motivation was based on the total number of participants in the group who introduced or agreed with a statement, rather than the number of times a statement or topic was raised or agreed with by a single participant.

\subsection{Transcription and content analysis}

Audio recordings were transcribed by a team member (MLG) within 24 hours after each focus group. The RF then compared and matched written notes to transcripts to verify quotations and to add seat numbers and observations about consensus/lack of consensus about specific statements. No personally identifiable information was documented or transcribed. Results were analyzed by using standard qualitative content analysis methods. ${ }^{[18]}$ The content of transcripts was analyzed to identify patterns in the participants' perceived barriers and motivations to $\mathrm{HH}$ practice.

We used the WHO Guidelines on Hand Hygiene in Health Care $^{[1]}$ to identify themes and develop a codebook. The WHO Guidelines describe and list the most common barriers and motivations shaping $\mathrm{HH}$ practice identified in multiple international studies. The codebook was drafted creating one code for each type of theme in the barrier or motivation 
categories. The barriers to $\mathrm{HH}$ (factors in poor adherence) identified in the Guidelines comprised 6 themes which were adopted for use in the process of coding focus group transcripts: 1) lack of supplies or infrastructure (materials) for $\mathrm{HH}$ or negative effects of available supplies on users (e.g., hand irritation/dryness); 2) lack of time for $\mathrm{HH}$; 3 ) social or interpersonal factors (e.g., lack of group support for ensuring $\mathrm{HH}$ practice); 4) institutional culture (e.g., a culture of $\mathrm{HH}$ noncompliance, lack of institutional role models); 5) lack of $\mathrm{HH}$ training and promotion (e.g., lack of knowledge, experience); and 6) staff perceptions, attitude, or culture (e.g., absence of personal accountability). After a preliminary review of focus group content, additional codes were created to account for site-specific or novel themes: a reported rush to return home after shift, the traditional obligation to shake hands with family members before patient contact, indigenous families' perception of prejudice against them, and patient and family culture (e.g., language and literacy barriers, no customary $\mathrm{HH}$ practice in their community).

The second overall response category was motivations for $\mathrm{HH},{ }^{[1]}$ subdivided into the themes of (1) normative beliefs (e.g., peer behavior or peer pressure), (2) control beliefs (e.g., perception that $\mathrm{HH}$ is easy to perform), and (3) attitudes (e.g., perceived high public health threat, protecting staff from infection, translation of early $\mathrm{HH}$ training into the professional setting).

Finally, participants' suggestions for improving the $\mathrm{HH}$ program and compliance were analyzed by creating a set of site-specific codes based on a review of focus group statements. These included recommendations related to training, material resources, infection rates, promotional campaigns, sanctions, and "other" suggestions.

After codes were established and tested, each transcript was searched for the code words and phrases, taking into account the rules of disambiguation. ${ }^{[16]}$ The two coders (RF and MLG) compared coding results and discussed discrepancies in codes. After discussion these discrepancies were reconciled, resulting in greater than $80 \%$ inter-coder consistency/agreement; this rate of agreement matches qualitative text analysis standards. ${ }^{[18]}$ Relevant content was coded and cross-checked for coding consistency and reliability. To identify meaningful relationships among words and word strings, codes were sorted by theme and analyzed by frequency and association with job type and individual respondent. These results yielded a text-by-theme profile matrix identifying the strength of themes and patterns within and across focus groups (e.g., intragroup and intergroup patterns in nurses, physicians, auxiliary staff, and support staff) and their possible relation to variables such as gender, age, status, and years of experience. Several recent studies have validated this pro- cedure for coding and analyzing focus group data. ${ }^{[3,17,19,20]}$

\section{RESULTS}

\subsection{Focus group}

Fifty-five hospital staff ( 46 female, 9 male) participated in the 6 focus group sessions. Participants comprised 8 nurse supervisors, 12 general nurses, 8 auxiliary nurses, 8 physicians, and 19 auxiliary staff ( 2 respiratory therapists, 4 pharmacists, 2 laboratory technicians, 2 nutritionists, 1 general physical therapy nurse, 5 cleaning staff, and 3 volunteers) (see Table 2).

\subsection{Barriers to $\mathrm{HH}$ Practice}

Staff who participated in focus groups viewed HH compliance as a struggle and cited multiple barriers. Some themes were common to the WHO list of barriers to $\mathrm{HH}$, particularly inadequate infrastructure and time pressure. However, other reported barriers appeared to be distinctive to the setting and culture. An overarching perception among the participants was that they lacked both control over HH compliance and the power to eliminate barriers to compliance.

\subsubsection{Infrastructure}

Focus group participants agreed that the supply, quality, and distribution of $\mathrm{HH}$ materials was far better at UNOP than at the adjacent Roosevelt Hospital, where one sink might be shared by an entire floor. However, the focus groups specified $\mathrm{HH}$ infrastructure deficiencies that were subsequently verified by a study team tour of the facility. These deficiencies included the absence of $\mathrm{HH}$ stations at clinic entrances and the depletion of alcohol gel, soap, and/or disposable towels, which might go unnoticed for weeks. A few gel dispensers required strenuous effort to dispense the product, and others were mounted in such a way that contaminated hands exposed surrounding areas while reaching the dispensers. Some staff members reported that the alcohol gel had an unpleasant odor, damaged the skin and nails, or caused hands to become sticky and "heavy" after repeated use. Comments included, "For me, it gives me allergies," "My skin peels," and "It feels as if the gel glues my hands."

\subsubsection{Time pressure and work load}

Almost all participants agreed that time constraints, patient load, and urgent tasks intruded on HH compliance. Nurses, therapists, and other staff must attend to multiple patients several times per day, and physicians and other staff divide their daily clinical responsibilities of UNOP with outside clinics in the city. Participants stated, "Perhaps the number of patients means that compliance cannot be maintained" and "... it has to do with the number of patients... when one is engaged in so much activity, at times I forget the act of washing hands."

ISSN 1925-4040 E-ISSN 1925-4059 
Table 2. Composition of focus groups and most frequent responses

\begin{tabular}{|c|c|c|c|c|c|c|}
\hline \multirow{2}{*}{$\begin{array}{l}\text { Focus } \\
\text { Group }\end{array}$} & \multirow{2}{*}{$\begin{array}{l}\text { Job } \\
\text { Category }\end{array}$} & \multicolumn{3}{|c|}{ Number of Participants } & \multirow{2}{*}{ Job Type (n) } & \multirow{2}{*}{$\begin{array}{l}\text { Most Frequent Responses according to Category and } \\
\text { Themes ( } n \text { /total) }\end{array}$} \\
\hline & & Total (n) & Male (n) & Female $(n)$ & & \\
\hline 1 & $\begin{array}{l}\text { Nurse } \\
\text { supervisors }\end{array}$ & 8 & 1 & 7 & Head Nurses (8) & $\begin{array}{l}\text { Barrier: Perception: There is no culture of responsibility } \\
\text { or habit of HH. (6/8) } \\
\text { Motivation: Attitude: Awareness that it protects the } \\
\text { patient. (4/8) }\end{array}$ \\
\hline 2 & Nurses & 12 & 1 & 11 & $\begin{array}{l}\text { General nurses (11), } \\
\text { Charge nurse (1) }\end{array}$ & $\begin{array}{l}\text { Barrier: Materials: Sometimes HH stations lack } \\
\text { supplies. (8/12) } \\
\text { Motivation: Attitude: Awareness that it protects the } \\
\text { patient. (7/12) }\end{array}$ \\
\hline 3 & $\begin{array}{l}\text { Auxiliary } \\
\text { nurses }\end{array}$ & 8 & 1 & 7 & Auxiliary nurses (8) & $\begin{array}{l}\text { Barriers: } \\
\text { 1) Social: HH not promoted at personal or institutional } \\
\text { level. (4/8) } \\
\text { 2) Social: “Infection control” is not my responsibility. } \\
\text { (4/8) } \\
\text { 3) Social: Negative reaction to reminders about HH. } \\
\text { (4/8) } \\
\text { Motivations: } \\
\text { 1) Attitude: Awareness that it protects the patient. (7/8) } \\
\text { 2) Attitude: Self-protection. (6/8) } \\
\text { 3) Attitude: Protect family when participant returns } \\
\text { home. (4/8) }\end{array}$ \\
\hline 4 & Physicians & 8 & 2 & 6 & Pediatricians (8) & $\begin{array}{l}\text { Barrier: Time: Insufficient time. }(8 / 8) \\
\text { Motivation: Norm: Role model and pressure from peers. } \\
(8 / 8)\end{array}$ \\
\hline 5 & $\begin{array}{l}\text { Auxiliary } \\
\text { staff }\end{array}$ & 11 & 1 & 10 & $\begin{array}{l}\text { Respiratory therapy } \\
\text { (2), Pharmacy (4), } \\
\text { Clinical micro lab } \\
\text { (2), Nutrition (2), } \\
\text { General therapy } \\
\text { nurse (1) }\end{array}$ & $\begin{array}{l}\text { Barrier: Social: Negative reaction to giving reminders } \\
\text { for HH. (11/11) } \\
\text { Motivation: Attitude: Awareness that it protects the } \\
\text { patient. (6/11) }\end{array}$ \\
\hline 6 & $\begin{array}{l}\text { Volunteers } \\
\text { and auxiliary } \\
\text { staff }\end{array}$ & 8 & 3 & 5 & $\begin{array}{l}\text { Cleaning staff (5), } \\
\text { Volunteers (3) }\end{array}$ & $\begin{array}{l}\text { Barrier: Perception: Use of gloves obviates the need for } \\
\text { HH. (4/8) } \\
\text { Motivations: } \\
\text { 1) Attitude: Self-protection when performing an activity } \\
\text { in which there is high risk of contamination via patient } \\
\text { contact. (3/8) } \\
\text { 2) Attitude: Awareness that it protects the patient. (3/8) }\end{array}$ \\
\hline
\end{tabular}

Physicians were most likely to admit to periodic noncompliance, citing emergencies as the most common reason. Comments included, "When we attend to an emergency, the priority is the patient and we may skip handwashing," "A majority of times the problem is emergencies... and external consults... are sometimes very far away and... conditions are difficult." Observational data on $\mathrm{HH}$ compliance collected by UNOP's ICP team reinforced the conclusion that the rush to attend emergency cases overrode concerns about HH (personal information, August 2011).

While supplies and patient load are cited in the WHO Guide-

lines as frequent barriers to $\mathrm{HH},{ }^{[1]}$ our focus group participants raised three additional concerns which are site-specific or culturally distinctive.

\subsubsection{Insufficient training}

Focus group participants reported that volunteers, medical students, and family members are not instructed about $\mathrm{HH}$ and that new staff may wait months for training. Comments included, "Medical students never wash their hands"; "We have more than twenty new staff every month"; "New personnel are not conscientious about hand hygiene." When asked what they recalled about their previous $\mathrm{HH}$ education, most 
participants remembered hospital-wide announcements promoting infection control. Only 2 of the 55 participants who had completed HH training remembered the "powder and [ultraviolet] lamp" visual demonstration of how contaminants invisible to the eye can cling to hands.

\subsubsection{Organizational culture and social norms}

Non-physician personnel, especially the nursing staff, cited the hospital hierarchy as a major barrier to a culture of $\mathrm{HH}$. Participants occasionally received recognition for their efforts to promote compliance, but many feared that their reminders to practice $\mathrm{HH}$ would be met by defensive or hostile reactions. None were willing to advocate $\mathrm{HH}$ practice to staff above them in rank, and a few cited fear of job loss. Previous studies have shown that pervasive and intractable clinical hierarchies can hamper infection control efforts. ${ }^{[21,22]}$ Participants stated, "Some people have a negative reaction when I remind them about correct hand hygiene practice"; "Some physicians would not accept a suggestion from us [nurses]"; and "I feel it is administrative personnel who don't have the culture of washing hands, because they also pass through and touch the doors, and they don't think to wash their hands.' Perhaps because of these concerns, a few participants concluded that promoting $\mathrm{HH}$ compliance is simply not their concern and that $\mathrm{HH}$ enforcement rests with specialists. As one participant remarked, "It is not my responsibility to remind my co-workers; there is an infection control team for that."

\subsubsection{Ignorance of infection risk among visitors, espe- cially indigenous Mayans}

Nurses, auxiliary staff, and especially volunteers, who had the greatest interaction with patients and families, most often mentioned visitors as uninformed about infection risk and cited culture and language as barriers. This concern was most prevalent in relation to visitors and family from traditional Mayan communities. This result is consistent with previous findings that Guatemala's elite and Mestizo populations perceive indigenous Mayan culture and practices as below public health standards; ${ }^{[23]}$ it is also consistent with more privileged groups' assumptions about hygiene and contamination in indigenous Guatemalan communities. ${ }^{[24]}$ Participants' comments reflected these beliefs; for example, "They do not have hygiene habits. It is cultural"; "An important percentage of our patients belong to different indigenous groups, so that communication is an issue"; and "There are some cultural beliefs, [such as] that bathing is unhealthy while the patient is febrile."

Many focus group participants, especially nurses and volunteers, believed that infection is brought in by Mayan parents, siblings and other visitors. Several identified the practice of handshakes during greetings, common greeting behavior in Guatemala, as a cause of cross-contamination, saying "They offer a hand shake with dirty hands." One male nurse reported that he avoids contamination by asking family members to touch the top of his head "as a blessing" before treating the patient. Participants reported that they frequently advise patients' parents about hygiene but that family members ignore them, become angry, or do not understand. "I believe it's important to educate the parents and also the patients... to wash their hands," but "There are certain parents who laugh... You reach a point where you don't want to say anything. It's not all, but some can't get the importance of hygiene into their heads."

Staff members in frequent contact with patients and visitors were also most likely to find communication a challenge to infection control. Several cited Guatemala's profuse linguistic diversity, comprising more than 30 language variants, as an impediment to explaining and enforcing HH. For example, "Some parents don't speak Castellano... they say they understand but they don't.... there are many languages" and "It's not possible to recruit a translator who speaks all the languages."

Some healthcare workers described insufficient understanding of infection transmission within the indigenous culture. Other participants argued that parents resist infection control efforts and file discrimination complaints when told to practice HH. Comments included, "It's a way of life that they don't have the custom of washing their hands"; "There was one parent whose baby had long, sharp nails and I asked to cut them. He said if I cut them the baby would not be able to speak"; and "I feel it's principally the parents... Many times they're bringing food from the outside... and we don't know if they wash."

\subsection{Motivations for $\mathrm{HH}$ practice}

Our content analysis identified two themes related to staff motivation to practice $\mathrm{HH}$.

\section{Patient protection}

All participants agreed that regardless of the motivation for it, $\mathrm{HH}$ protects patients. One participant commented, "I know that hand hygiene prevents patient infections," while another noted, "I am responsible for reducing the risk of cross-infection in my patients." A few participants noted that protecting patients from infection also improves cancer outcomes and reduces costs by preventing longer hospitalization.

\subsection{Self-protection}

A large proportion of participants, especially those who had the greatest direct contact with patients, also cited self- 
protection as a motive for HH. Participants reported that they were most likely to engage in $\mathrm{HH}$ when they felt they had been contaminated. The desire to practice $\mathrm{HH}$ was strongest after examining a patient, touching patient secretions, touching visitors (e.g., shaking hands), using the restroom, or using a room they felt was "dirty." One staff member added that contact can also be "emotionally dirty." Participants reported feeling the need for $\mathrm{HH}$ "when I have contact with blood products" (nurse); "[because] I don't want to take any bacteria from the hospital to my family" (volunteer); "when it is indicated, because I know there are different bacteria that we isolate in the laboratory" (lab technician); and "after providing care to any 'septic' patient" (auxiliary nurse).

One self-protective belief, especially among the cleaning and volunteer staff, is in itself a barrier to $\mathrm{HH}$ : the widespread perception that silicone gloves offer sufficient protection. These support staff were not aware that gloves themselves can cross-contaminate surfaces and ultimately protect only the wearer, while increasing the infection risk to patients and others.

\section{Discussion}

Compliance with good $\mathrm{HH}$ practice is essential to prevent infection and improve outcomes, especially among oncology patients. Our focus groups revealed the main elements that encouraged or discouraged $\mathrm{HH}$ compliance in the UNOP pediatric cancer unit. Perceived barriers to the practice of $\mathrm{HH}$ were insufficient time, negative reaction when giving reminders for $\mathrm{HH}$, inconsistent presence of supplies, inconsistent $\mathrm{HH}$ training, suboptimal peer and supervisor $\mathrm{HH}$ practices and social norms, and patients' and families' limited knowledge about preventing infection. These challenges at UNOP are also frequently encountered at other centers in $\mathrm{LMICs}^{[25]}$ and should be specifically addressed by IPC teams and healthcare institution leaders to increase compliance over the long term.

The information obtained through our focus groups pointed out important deficiencies at UNOP that preclude a climate of safety favorable for compliance with $\mathrm{HH}$. Participants in the focus groups reported being discouraged by negative responses when they reminded family members, peers, and superiors to practice HH. They described lack of consistency in training new personnel, students, and patient families in HH. Additionally, understaffing was also mentioned by the participants. These themes reflect the attitudes and culture of the unit, which must support a climate of safety to promote $\mathrm{HH}$. The WHO has identified several components necessary for high-safety climate in healthcare settings, these are: 1) attitudes and perceptions of personnel about safety; 2) institutional procedures, structures, and resources for safety; 3 )

Published by Sciedu Press appropriate safety training; and 4) routine monitoring of processes and safety standards (1). Adherence to $\mathrm{HH}$ requires that appropriate $\mathrm{HH}$ policies and procedures be coupled with an adequate number of adequately trained personnel. Since the focus groups study, the UNOP's ICP team has worked to improve $\mathrm{HH}$ education and encourage the hospital's leadership to assure consistent availability of $\mathrm{HH}$ supplies and importantly, to expand the number of healthcare provider staff, especially nursing.

UNOP staff members reported the perception that hygiene is lacking among patients' families, especially those from traditional Mayan communities, who face language barriers and limited understanding of infection. Family hygiene is especially important at UNOP, where parents participate in the care of their hospitalized child. In 2011, 17\% (55 of 321) of patients at UNOP were from traditional Mayan communities. Our findings suggest that the care provided by these parents can be improved if educational interventions are tailored to their language and sociocultural background. Mayan-speaking UNOP staff can also be of help in improving the general staff understanding of Mayan families' customs and perceptions and in enhancing communication with these families. Our findings illustrate that in other LMICs centers where $\mathrm{HH}$ instruction and expectation of compliance are affected by diverse ethnic populations, dialects, and levels of education, a special accommodation must be made for family instructions, preferable using culturally and linguistically competent staff.

The most frequently cited motivation for $\mathrm{HH}$ practice was patient protection, followed by self-protection. The specialized care needed by the patients at UNOP and their vulnerability to serious infection may explain the high priority given to protecting these patients. The physicians' focus group was the only group in our study that did not cite patient protection as the main motivation for $\mathrm{HH}$. In the literature, low $\mathrm{HH}$ compliance is often observed and reported among physicians, and this can be as low as $31.1 \%$ in some publications. ${ }^{[26,27]}$ Pediatric cancer care services in LMICs such as UNOP, often have a limited number of oncologists and supportive care capability, ${ }^{[28]}$ including lack of trained personnel, infrastructure, and supplies for safe healthcare practices. These challenges are additional barriers for the practice of HH. In high-income countries such as the United States, patient protection is a strong financial motivator at the institutional level because of possible refusal of insurers to reimburse for conditions such as HAIs ${ }^{[29]}$ and possible legal liability. ${ }^{[30]}$ Furthermore, patient protection criteria must be met for a facility's accreditation. ${ }^{[31]}$ These external motivations may not be strong incentives in LMICs, where rates of medical insurance can be very low, ${ }^{[32]}$ legal liability for healthcare-associated condi- 
tions is only starting to emerge, and institutional accreditation is rarely required. ${ }^{[33,34]}$ In LMICs, self-protection has been reported more often as the primary motivation for $\mathrm{HH}$ among healthcare workers. ${ }^{[3,12,17]}$ Capitalizing on motivation coupled with the presence of $\mathrm{HH}$ infrastructure and supplies, and the healthcare provider's capability of performing $\mathrm{HH}$ have been shown to be helpful for practicing $\mathrm{HH}$, and possibly sustaining this practice over time. ${ }^{[35]}$

Focus group studies can reveal crucial problems in practicing $\mathrm{HH}$. One study conducted in China ${ }^{[36]}$ found that $\mathrm{HH}$ compliance remained low despite health care staff's positive attitude toward $\mathrm{HH}$ and improved $\mathrm{HH}$ knowledge. This low compliance was found to be because of lack of resources and authorities' low prioritization of infection prevention enforcement. Another focus group study at a teaching hospital in rural India ${ }^{[7]}$ found that participants understood the importance of $\mathrm{HH}$ in preventing infection, although water and $\mathrm{HH}$ stations were not readily available and institutional policies and education were lacking. Our results agree, in part, with these recent findings; our participants perceived the importance of weak organizational support of $\mathrm{HH}$ and placed comparatively less emphasis on perceived deficiencies in the quality and availability of HH supplies. Despite better rating of $\mathrm{HH}$ resources at UNOP compared with the $\mathrm{HH}$ resources at the attached hospital, Hospital Roosevelt, the UNOP staff stressed that at UNOP there were some supply deficiencies in quality and availability, for example, the gel was sticky and $\mathrm{HH}$ resources were insufficient, e.g. not enough sinks, not enough working and accessible dispensers at the point of care, or next to exits. $\mathrm{HH}$ focus groups in high-income countries can reveal some findings similar to those in LMICs, with some site specific differences. A recent focus group study at a teaching hospital in Canada found that workload and urgent care demands made $\mathrm{HH}$ compliance difficult, and participants expressed greater confidence in their own judgment than in the guidelines for when to practice $\mathrm{HH}$, which they felt were very conservative. ${ }^{[17]}$ In the same study, participants cited the importance of institutional support to maintain sufficient $\mathrm{HH}$ supplies and the importance of physician role models. In Belgium, a survey of nursing staff in the intensive care unit of a university hospital found that determinants predicting poor $\mathrm{HH}$ compliance were reports of poor self-efficacy or attitude toward time-related barriers. ${ }^{[14]}$ These studies, like ours, aimed to gain direct, institution-specific knowledge for use in targeted interventions to improve $\mathrm{HH}$.

The limitations of our study include our convenience sampling and the possibility that not all opinions were freely expressed due to fear of reprisal. However, we believe that the opinions shared were candid and complete, as participants were grouped by job category and assured at the beginning and end of each session that their statements and their identities would remain confidential (available only to the study team). To this end, participants were identified only by chair number in study documents. Further, the group moderators were not employees of UNOP.

To our knowledge, this was the first focus group study of $\mathrm{HH}$ at a pediatric cancer unit in a Latin American LMIC. Many of our findings can be generalized to similar settings, and our methods may be replicated to identify institution-specific factors that influence the likelihood of appropriate $\mathrm{HH}$ practice, with the goal of targeted improvement of resources and training to reduce healthcare-associated infections. Our results suggest that in addition to $\mathrm{HH}$ resources, continuous education and training are needed to achieve and maintain high levels of $\mathrm{HH}$ compliance. Gaining institutional support is essential and this can be aided by demonstrating data of the outcome and cost-saving of better compliance with $\mathrm{HH}$, and with decreasing the number of infections and duration of hospital stay. ${ }^{[37]}$ More importantly, the design of $\mathrm{HH}$ improvement efforts must address local sociocultural factors.

\section{ACKNOWLEDGEMENTS}

We thank Sharon Naron for editing the manuscript. This work was supported by ALSAC.

\section{CONFlicts OF InTEREST Disclosure}

The authors declare that there is no conflict of interest.

\section{REFERENCES}

[1] World Health Organization. WHO Guidelines on hand Hygiene in Health Care: First Global Patient Safety Challenge: Clean Care is Safer Care. Geneva, Switzerland. 2009.

[2] Sax H, Uckay I, Richet H, et al. Determinants of good adherence to hand hygiene among healthcare workers who have extensive exposure to hand hygiene campaigns. Infect Control Hosp Epidemiol. 2007; 28: 1267-74. PMid:17926278. http://dx.doi.org/10.10 $86 / 521663$

[3] Erasmus V, Brouwer W, van Beeck EF, et al. A qualitative exploration of reasons for poor hand hygiene among hospital workers: lack of positive role models and of convincing evidence that hand hygiene prevents cross-infection. Infect Control Hosp Epidemiol. 2009; 30: 415-9. PMid:19344264. http://dx. doi .org/10.1086/596773

[4] Whitby M, McLaws ML, Slater K, et al. Three successful interventions in health care workers that improve compliance with hand hygiene: is sustained replication possible? Am J Infect Control. 2008; 36: 349-55.

[5] Bischoff WE, Reynolds TM, Sessler CN, et al. Handwashing compliance by health care workers: The impact of introducing an accessible, 
alcohol-based hand antiseptic. Arch Intern Med. 2000; 160: 1017-21. http://dx.doi.org/10.1001/archinte.160.7.1017

[6] Alp E, Leblebicioglu H, Doganay M, et al. Infection control practice in countries with limited resources. Ann Clin Microbiol Antimicrob. 2011; 10: 36. PMid:22018286. http://dx.doi.org/10.1186/1 476-0711-10-36

[7] Joshi SC, Diwan V, Tamhankar AJ, et al. Qualitative study on perceptions of hand hygiene among hospital staff in a rural teaching hospital in India. J Hosp Infect. 2012; 80: 340-4.

[8] Gupta S, Antillon FA, Bonilla M, et al. Treatment-related mortality in children with acute lymphoblastic leukemia in Central America. Cancer. 2011; 117: 4788-95. PMid:21446043. http: //dx.doi.org/10.1002/cncr.26107

[9] Gupta S, Bonilla M, Valverde P, et al. Treatment-related mortality in children with acute myeloid leukaemia in Central America: incidence, timing and predictors. Eur J Cancer. 2012; 48: 13639. PMid:22082459. http://dx.doi.org/10.1016/j.ejca.20 11.10 .009

[10] Melgar M, De-Leon RE, Geronimo M, et al. How we optimized prevention and control of pandemic 2009 influenza A (H1N1) in a resource-limited nation's pediatric oncology unit. Am J Infect Control. 2011; 39: 534-5. PMid:21612844. http://dx.doi.org/10. 1016/j.ajic.2010.10.012

[11] Caniza MA, Maron G, McCullers J, et al. Planning and implementation of an infection control training program for healthcare providers in latin america. Infect Control Hosp Epidemiol. 2007; 28: 1328-33. PMid:17994511. http://dx.doi.org/10.1086/521655

[12] Whitby M, McLaws ML, Ross MW. Why healthcare workers don't wash their hands: a behavioral explanation. Infect Control Hosp Epidemiol. 2006; 27: 484-92.

[13] Whitby M, Pessoa-Silva CL, McLaws ML, et al. Behavioural considerations for hand hygiene practices: the basic building blocks. J Hosp Infect. 2007; 65: 1-8. PMid:17145101. http://dx. doi .org $/ 10.1016 / j \cdot j$ hin.2006.09.026

[14] De WD, Maes L, Labeau S, et al. Behavioral determinants of hand hygiene compliance in intensive care units. Am J Crit Care. 2010; 19: 230-9. PMid:20436062. http://dx.doi.org/10.4037/ajc c2010892

[15] Krueger RA, Casey MA. Focus Groups: A Practical Guide for Applied Research. 4th ed. Los Angeles: Sage. 2009.

[16] Schensul JJ, LeCompte MD, Nastasi BK, et al. Enhanced Ethnographic Methods: Audiovisual Techniques, Focused Group Interviews, and Elicitation (Ethnographer's Toolkit). Walnut Creek, CA: Altamira Press. 1999.

[17] Jang JH, Wu S, Kirzner D, et al. Focus group study of hand hygiene practice among healthcare workers in a teaching hospital in Toronto, Canada. Infect Control Hosp Epidemiol. 2010; 31: 144-50. PMid:20017635. http://dx.doi.org/10.1086/649792

[18] Bernard HR. Research Methods in Anthropology: Qualitative and Quantitative Approaches. 5th ed. Lanham, Md: AltaMira Press. 2011.

[19] Gafos M, Mzimela M, Ndlovu H, et al. "One teabag is better than four": Participants response to the discontinuation of $2 \%$ PRO2000/5 microbicide gel in KwaZulu-Natal, South Africa. PLoS One. 2011; 6: e14577.

[20] Rojjanasrirat W, Sousa VD. Perceptions of breastfeeding and planned return to work or school among low-income pregnant women in the USA. J Clin Nurs. 2010; 19: 2014-22. PMid:20920027. http: //dx.doi.org/10.1111/j.1365-2702.2009.03152.x

[21] Singer SJ, Falwell A, Gaba DM, et al. Identifying organizational cultures that promote patient safety. Health Care Manage Rev. 2009;
34: 300-11. PMid:19858915. http://dx.doi.org/10.1097/HMR .0b013e3181afc10c

[22] Smith CA. Race-Class-Gender Ideology in Guatemala: Modern and Anti-Modern Forms. Comparative Study of Society and History. 1995; 37: 723-49. http://dx.doi.org/10.1017/S001041 7500019939

[23] McCrea H. Diseased Relations: Epidemics, Public Health, and StateBuilding in Yucatán, Mexico, 1847-1924. Albuquerque, NM: University of New Mexico Press. 2011.

[24] Goldman N, Pebley AR, Beckett M. Diffusion of ideas about personal hygiene and contamination in poor countries: evidence from Guatemala. Soc Sci Med. 2001; 52: 53-69. http://dx. doi .org/1 $0.1016 / \mathrm{S} 0277-9536(00) 00122-2$

[25] Caniza MA, Odio C, Mukkada S, et al. Infectious complications in children with acute lymphoblastic leukemia treated in lowmiddle-income countries. Expert Rev Hematol. 2015; 8: 627451. PMid:26211675. http://dx.doi.org/10.1586/17474086. 2015.1071186

[26] Boyce JM, Pittet D. Guideline for Hand Hygiene in Health-Care Settings: recommendations of the Healthcare Infection Control Practices Advisory Committee and the HICPAC/SHEA/APIC/IDSA Hand Hygiene Task Force. Infect Control Hosp Epidemiol. 2002; 23 Suppl 12: S3-40.

[27] Pittet D, Hugonnet S, Harbarth S, et al. Effectiveness of a hospitalwide programme to improve compliance with hand hygiene. Infection Control Programme. Lancet. 2000; 356: 1307-12. http: //dx.doi.org/10.1016/S0140-6736(00) 02814-2

[28] Kruger M, Hendricks M, Davidson A, et al. Childhood cancer in Africa. Pediatr Blood Cancer. 2014; 61: 587-92. PMid:24214130. http://dx.doi.org/10.1002/pbc.24845

[29] Centers for Medicare and Medicaid Services. Medicaid program; payment adjustment for provider-preventable conditions including health care-acquired conditions. Final rule. Fed Regist. 2011; 76: 32816-38.

[30] Gardam MA, Lemieux C, Reason P, et al. Healthcare-associated infections as patient safety indicators. Healthc Pap. 2009; 9: 8-24. http://dx.doi.org/10.12927/hcpap.2009.20922

[31] Joint Commission International Accreditation Standards for Hospitals. 5th edition. Oakbrook Terace, Illinois: The Joint Commission. 2014.

[32] Lagomarsino G, Garabrant A, Adyas A, et al. Moving towards universal health coverage: health insurance reforms in nine developing countries in Africa and Asia. Lancet. 2012; 380: 933-43. http://dx.doi.org/10.1016/S0140-6736(12)61147-7

[33] Adwok J. Respondeat Superior Tort Liability and Surgical Errors in Low Income Countries: An Overview. Journal of Biology, Agriculture and Healthcare. 2013; 3: 131-5.

[34] Smits H, Supachutikul A, Mate KS. Hospital accreditation: lessons from low- and middle-income countries. Globalization and Health. 2014; 10: 1-8.

[35] Lhakhang P, Lippke S, Knoll N, et al. Evaluating brief motivational and self-regulatory hand hygiene interventions: a cross-over longitudinal design. BMC Public Health. 2015; 15: 79. PMid:25649150. http://dx.doi.org/10.1186/s12889-015-1453-7

[36] Yuan CT, Dembry LM, Higa B, et al. Perceptions of hand hygiene practices in China. J Hosp Infect. 2009; 71: 157-62. PMid:19013685. http://dx.doi.org/10.1016/j.jhin.2008.09.017

[37] Cummings KL, Anderson DJ, Kaye KS. Hand hygiene noncompliance and the cost of hospital-acquired methicillin-resistant Staphylococcus aureus infection. Infect Control Hosp Epidemiol. 2010; 31: 357-64. PMid:20184440. http://dx.doi.org/10.1086/651096 